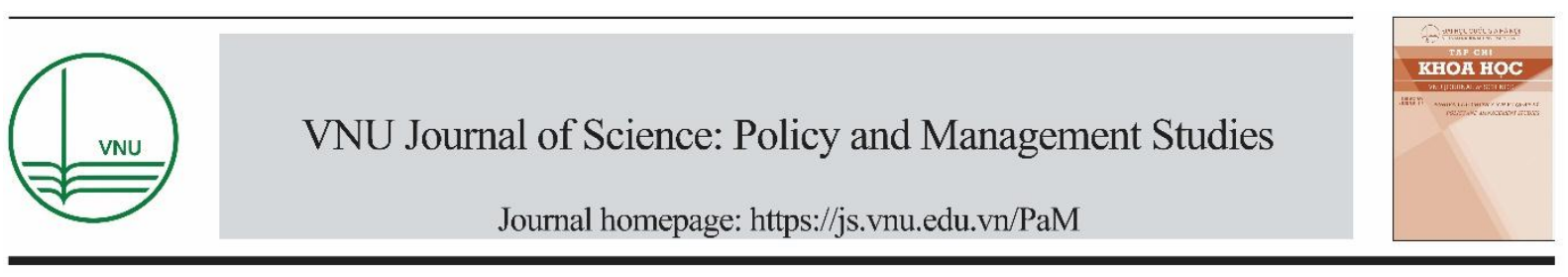

Original Article

\title{
Population Structure Change in the Mekong Delta: Current and Policy Implications
}

\author{
Phan Thuan* \\ Academy of Polictics Region IV, No 6 Nguyen Van Cu, Ninh Kieu, Can Tho, Viet Nam \\ Received 03 March 2020 \\ Revised 12 March 2020; Accepted 15 March 2020
}

\begin{abstract}
Shift in the population structure is one of the factors that impacts strongly on socioeconomic development. The purpose of the article is to analyze the current of population structure shift in oder to shows clearly the population development trend in the Mekong Delta. Based on this, the article points out some problems posed from the trend of population structure change such as the risk of sex imbalance at birth, the elderly population feminization and the impact of population aging, the risk of losing the golden population opportunities. The author then some recommendations implied policies are proposed to solve the threats and challenges created by the process of changing population structure.
\end{abstract}

Keywords: Population structure, Shift in population, Population aging, Golden population, Sex ratio.

\footnotetext{
* Corresponding author.

E-mail address:
}

https://doi.org/10.25073/2588-1116/vnupam.4221 


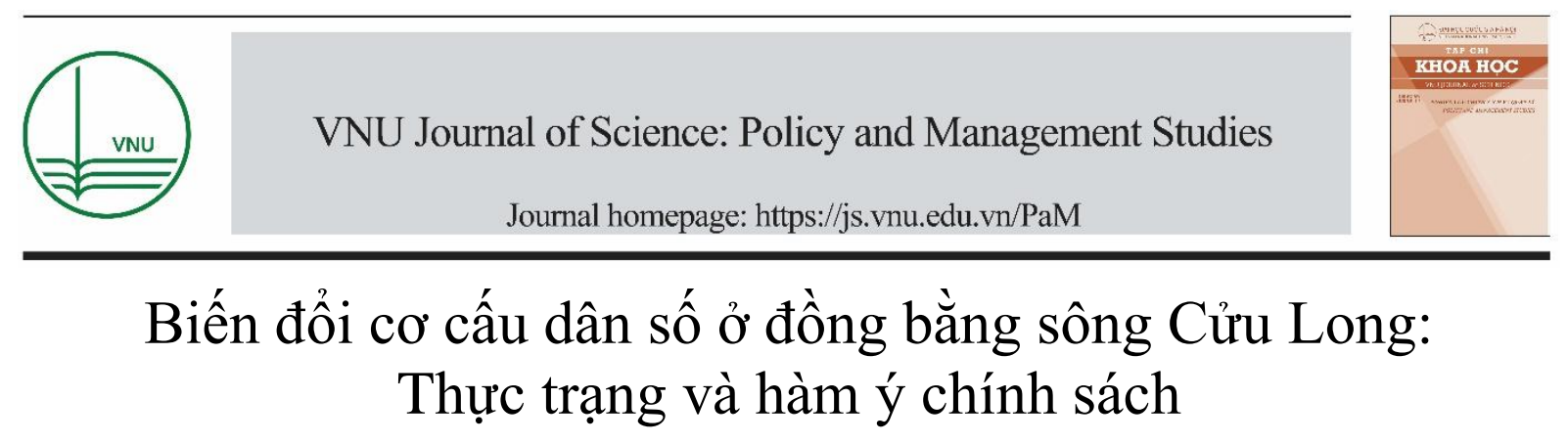

\author{
Phan Thuận* \\ Học viện chính trị khu vục IV, 6 Nguyễn Văn Cù, Ninh Kiều, Cần Tho; Việt Nam \\ Nhận ngày 03 tháng 3 năm 2020 \\ Chỉnh sửa ngày 12 tháng 3 năm 2020; Chấp nhận đăng ngày 20 tháng 3 năm 2020
}

\begin{abstract}
Tóm tắt: Biến đổi cơ cấu dân số là một trong những yếu tố tác động mạnh mẽ đến phát triển kinh tế- xã hội. Mục đích của bài viết là phân tích thực trạng biến đổi cơ cấu dân số để thấy rõ xu hướng phát triển dân số ở đồng bằng sông Cửu Long. Trên cơ sở này, bài viết đã chỉ ra những vấn đề đặt ra từ xu hướng biến đối cơ cấu dân số như nguy cơ mất cân bằng giới tính khi sinh, "nữ hóa" dân số cao tuổi và tác động của già hóa dân số, nguy cơ mất cơ hội dân số vàng. Từ đó, đề xuất các kiến nghị hàm ý về chính sách để giải quyết những nguy cơ, thách thức được tạo ra từ quá trình biến đổi cơ cấu dân số.
\end{abstract}

Tù khóa: Cơ cấu dân số, biến đổi dân số, già hóa dân số, dân số vàng, tỷ số giới tính.

\section{Thực trạng biến đổi cơ cấu dân số ở đồng bằng sông Cửu Long}

Qua kết quả điều tra dân số và nhà ở năm 2019 cho thấy, đồng bằng sông Cửu Long (ĐBSCL) có khoảng 17,3 triệu người, tăng 1 triệu người so với năm 2009 [1], [2]. Điều này cho thây, quy mô dân số ở ĐBSCL có biến đổi theo xu hướng tăng trong 10 năm (2009-2019). Cùng với sự biến đổi về quy mô dân số thì cơ cấu dân số cũng có những biến đổi nhất định.

\subsection{Biến đổi cơ cấu dân số theo giới tính}

Một trong những đặc trưng cơ bản của co cấu dân số theo giới tính là tỷ số giới tính của

\footnotetext{
*Tác giả liên hệ.

Địa chỉ email:
}

https://doi.org/10.25073/2588-1116/vnupam.4221 dân số và tỷ số giới tính khi sinh. Trong 10 năm qua, cơ cấu dân số theo giới tính đã có những biến động.

Về tỷ số giới tính, tỷ số này được tính bằng dân số nam giới trên 100 nữ [2, tr57]. Theo kết quả điều tra dân số và nhà ở (2009), (2019) cho thấy, tỷ số giới tính ở ĐBSCL không có sự thay đổi (99 nam/100 nữ) (xem bảng 1). So với các vùng khác kinh tế- xã hội trong cả nước, tỷ số giới tính ở ĐBSCL ổn định trong 10 năm qua.

Xét ở các nhóm tuổi tại bảng 2 cho thấy, tỷ số giới tính dân số ở nhóm tuổi 0 -14 tuổi là cao nhất $(106,8$ nam/100 nữ) và thấp nhất ở nhóm tuổi từ 80 trở lên (48,4 nam/100 nữ), giảm dần theo độ tuổi; trong đó tỷ số này cân bằng ở nhóm tuổi 15-64. Xu hướng này diễn ra khá ổn định trong 10 năm qua, ngoại từ nhóm tuổi từ 80 trở lên có xu hướng giảm nhanh từ 63,7 nam/100 nữ của năm 2009 xuống còn 48,4 
nam/100 nữ. Điều này cho thấy, tuổi càng cao thì nam giới càng ít hơn phụ nữ .

Bảng 1. Tỷ số giới tính của vùng kinh tế- xã hội (nam/100 nữ)

\begin{tabular}{lll}
\hline Đặc điểm vùng kinh tế & 2009 & 2019 \\
\hline Trung du và miền núi phía Bắc & 99,9 & 100,9 \\
Đồng bằng sông Hồng & 97,2 & 98,3 \\
BắcTrung bộ và duyên hải Miền & & \\
Trung & 98,2 & 99,2 \\
Tây Nguyên & 102,4 & 101,7 \\
Đông nam bộ & 95,3 & 97,8 \\
Đồng bằng sông Cửu Long & 99,0 & 99,0 \\
\hline
\end{tabular}

(Nguồn: tính toán của tác giả từ TCTK, 2009, 2019)

Bảng 2. Tỷ số giới tính dân số theo nhóm tuổi (nam/100 nữ)

\begin{tabular}{lll}
\hline Nhóm tuổi & 2009 & 2019 \\
\hline $0-14$ tuối & 108,4 & 106,8 \\
$15-64$ tuổi & 100 & 100,9 \\
65 tuổi trở lên & 65,9 & 69,2 \\
80 tuổi trở lên & 63,7 & 48,4 \\
\hline
\end{tabular}

(Nguồn: tính toán của tác giả từ TCTK, 2009, 2019)

Tỷ số giới tính ở ĐBSCL có xu hướng diễn ra tương tự với cả nước, có sự khác biệt theo các nhóm tuổi, tuổi càng cao tỷ số giới tính càng thấp, cao nhất ở nhóm 0-4 tuổi $(110,3$ nam/100 nữ) và thấp nhất ở nhóm từ 80 tuổi trở lên $(48,6$ nam/100 nữ) [2, tr58].
Sở dĩ là do tỷ số giới tính bị tác động trực tiếp bởi mô hình sinh, chết ở cấp độ toàn quốc và bị tác động trực tiếp bởi mô hình sinh, chết và di cư, ở những nơi thu hút nhiều người di cư là nam giới sẽ làm gia tăng tỷ số giới tính và ngược lại. Bên cạnh những yếu tố tác động trực tiếp trên, rất nhiều yếu tố gián tiếp tác động đến tỷ số giới tính như chiến tranh, các chính sách liên quan đến dân số, các chính sách phát triển kinh tế, chính sách về xuất khẩu lao động và thu hút vốn đầu tư [2, tr58-59].

Về tỷ số giới tính khi sinh, tỷ số này được tính là một chỉ số thống kê được xác định bằng số trẻ em trai được sinh ra trên một trăm trẻ em gái. Tỷ số này thông thường là từ 104-106 trẻ em trai trên 100 trẻ em gái và giá trị của tỷ số này thường rất ổn định trong qua thời gian [3,tr7]. Ở bảng số liệu 3 cho thây, tỷ số giới tính khi sinh ở ĐBSCL vẫn duy trì trong khoảng 106,9-109,9 bé trai/100 bé gái trong suốt 10 năm qua; so với tỷ số giới tính khi sinh thông thường thì tỷ số giới tính khi sinh ở ĐBSCL có thể chấp nhận được. Tỷ số giới tính khi sinh và tình trạng mất cân bằng giới tính khi sinh có sự khác nhau giữa các các địa phương ở ĐBSCL cả thành thị và nông thôn (xem bảng 3 ).

Bảng 3.Tỷ số giới tính khi sinh theo địa phương và thành thị-nông thôn (bé trai/100 bé gái)

\begin{tabular}{lllllll}
\hline & $\mathbf{2 0 0 9}$ & \multicolumn{5}{c}{$\mathbf{2 0 1 9}$} \\
\cline { 2 - 6 } & Chung & Thành thị & Nông thôn & Chung & Thành thị & Nông thôn \\
\hline Toàn vùng & 109,9 & 113,4 & 108,9 & 106,9 & 105,1 & 107,5 \\
Long An & 102,9 & 109,2 & 101,9 & 119,8 & 112,3 & 121,2 \\
Tiền Giang & 111,1 & 121,0 & 109,7 & 96,9 & 96,7 & 97,0 \\
Bến Tre & 107,8 & 106,4 & 107,9 & 109,7 & 102,8 & 110,4 \\
Trà Vinh & 112,7 & 115,6 & 112,2 & 105,8 & 107,7 & 105,4 \\
Vĩnh Long & 112,3 & 128,7 & 110,9 & 112,7 & 87,8 & 118,3 \\
Đồng Tháp & 108,5 & 111,8 & 107,8 & 112,2 & 113,0 & 112 \\
An Giang & 113,7 & 115,6 & 113,1 & 113,2 & 104,2 & 117,7 \\
Kiên Giang & 110,6 & 116,7 & 108,5 & 97,7 & 112,4 & 93,1 \\
Cần Thơ & 114,1 & 112,1 & 117,6 & 99,7 & 95,4 & 109,1 \\
Hậu Giang & 107,6 & 110,0 & 107,0 & 102,6 & 102,7 & 102,6 \\
Sóc Trăng & 109,9 & 107,7 & 110,4 & 109,9 & 110,7 & 109,5 \\
Bạc Liêu & 109,3 & 104,1 & 111,4 & 109,1 & 110,2 & 108,8 \\
Cà Mau & 112,7 & 121,4 & 110,5 & 102,5 & 119,7 & 98,2 \\
\hline
\end{tabular}

(Nguồn: TCTK, 2009, 2019) 
Xét tỷ số giới tính khi sinh qua các năm trong giai đoạn 2009-2019 thì tỷ số này diễn biến khá phức tạp (xem biểu 1). Điều này có nghĩa rằng, việc kiểm soát tỷ số giới tính khi sinh ở ĐBSCL không bền vững.

Biểu 1. Tỷ số giới tính khi sinh ở ĐBSCL qua các năm từ 2009-2019

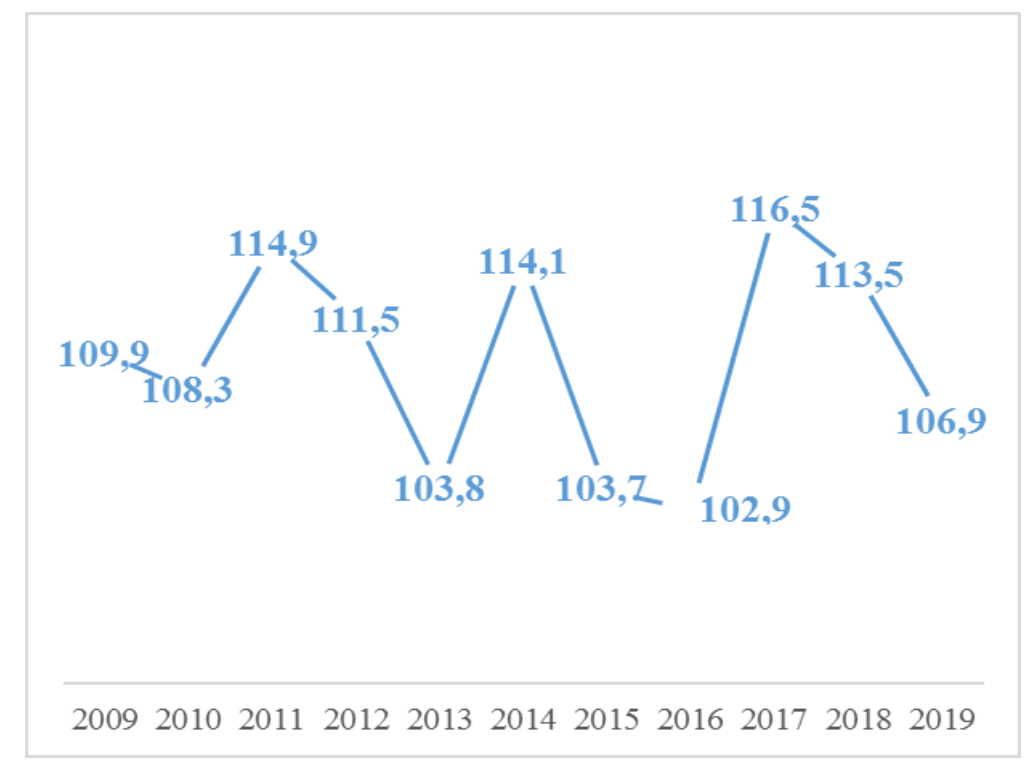

(Nguồn: TCTK, www.gso.gov.vn)

\subsection{Biến đổi cơ cấu dân số theo độ tuổi}

Cơ cấu dân số theo độ tuổi là một trong những đặc trưng cơ bản của cơ cấu dân số. Cho nên, phân tích cơ cấu dân số theo độ tuổi sẽ cho phép đánh giá về tình trạng phụ thuộc của dân số cũng như cơ hội tận dụng dư lợi của dân số vàng.

Về cơ cấu dân số vàng, cơ cấu dân số của một quốc gia được coi là trong thời kỳ cơ cấu dân số vàng khi nhóm dân số trẻ em (0-14 tuổi) chiếm tỷ trọng nhỏ hơn $30 \%$ và nhóm dân số người cao tuổi (từ 65 tuổi trở lên) chiếm tỷ trọng thấp hơn $15 \%$ trong tổng dân số [2, tr62]. Theo kết quả điều tra dân số và nhà ở năm 2019, tỷ trọng dân số dưới 15 tuổi ở ĐBSCL chiếm $22,0 \%$ và nhóm dân số từ 65 tuổi trở chiếm $8,4 \%$. Điều này có nghĩa là ĐBSCL đang trong thời kỳ dân số vàng. So với năm 2009, tỷ trọng dân số ở nhóm tuổi dưới 15 tuổi giảm $2,3 \%$ và nhóm dân số từ 65 tuổi trở lên tăng $2,4 \%$ (xem bảng 4). Như vậy, ĐBSCL vẫn duy trì giai đoạn dân số vàng trong suốt 10 năm qua.

Bảng 4. Cơ cấu dân số theo nhóm tuổi ở ĐBSCL năm 2009 và 2019

\begin{tabular}{lllll}
\hline \multirow{2}{*}{ Nhóm tuổi } & \multicolumn{2}{c}{2009} & \multicolumn{2}{c}{2019} \\
\cline { 2 - 5 } & Số lượng & Tỷ lệ $(\%)$ & Số lượng & Tỷ lệ (\%) \\
\hline Dưới 15 tuổi & 4.185 .451 & 24,36 & 3.807 .568 & 22,04 \\
Từ 15-64 tuổi & 11.946 .697 & 69,54 & 12.013 .005 & 69,55 \\
65+ & 1.046 .723 & 6,09 & 1.453 .057 & 8,41 \\
Tổng & 17.178 .871 & 100 & 17.273 .630 & 100 \\
\hline
\end{tabular}

(Nguồn: tính toán của tác giả từ TCTK, 2009, 2019) 
Tuy nhiên, tỷ trọng nhóm dân số từ $15-29$ tuổi và 50-64 tuổi đều tăng, lần lượt là $14,1 \%$ và $17,7 \%$; trong đó nhóm dân số từ 50-64 tuổi tăng nhanh hơn nhóm dân số từ 15-29 tuổi là 3,6\%; tỷ trọng nhóm dân số từ 30-49 tuổi giảm rất nhanh $(31,8 \%)$ trong 10 năm (xem bảng 5). Có thể nói, nhóm dân số từ 15-29 tuổi tăng nhưng không thay thế kịp thời cho già hóa của nhóm dân số trong độ tuổi từ 50-64. Điều này làm cho nguy cơ già hóa của nhóm dân số trong độ tuổi lao động.

Về tỷ lệ phụ thuộc, được xem là chỉ tiêu đánh giá gánh nặng của dân số trong độ tuổi lao động. Chỉ tiêu này phản ánh tác động của mức sinh, mức chết đến cơ cấu tuổi và lực lượng lao động $[4$, tr63]. Ở bảng số 6 cho thấy, tỷ lệ phụ thuộc trẻ ở ĐBSCL giảm và tỷ lệ phụ thuộc già tăng trong 10 năm (2009-2019). Trong đó, tỷ lệ thuộc già tăng nhanh từ $8,8 \%$ của năm 2009 lên $14,4 \%$ của năm 2019. Điều này phản ánh thực tế rằng, tỷ trọng dân số từ 65 tuồi trở lên có xu hướng tăng nhanh hơn so với các nhóm tuổi khác và tỷ lệ phụ thuộc già sẽ trở thành gánh nặng của dân số trong độ tuổi lao động, đặc biệt là ở khu vực nông thôn.

Bảng 5. Tỷ trọng dân số (15-64 tuổi) theo năm (\%)

\begin{tabular}{llll}
\hline Nhóm tuổi & 2009 & 2019 & Tăng/giảm \\
\hline 15-29 tuôi & 14,9 & 29,0 & 14,1 \\
30-49 tuổi & 78,2 & 46,4 & $-31,8$ \\
50-64 tuổi & 6,9 & 24,6 & 17,7 \\
Tổng & 100 & 100 & \\
\hline
\end{tabular}

(Nguồn: tính toán của tác giả từ TCTK, 2009, 2019)

Bảng 6. Tỷ số phụ thuộc ở ĐBSCL năm 2009 và 2019 (\%)

\begin{tabular}{lllllll}
\hline & \multicolumn{4}{c}{2009} & \multicolumn{3}{c}{2019} \\
\cline { 2 - 7 } & Chung & Thành thị & Nông thôn & Chung & Thành thị & Nông thôn \\
\cline { 2 - 7 } Tỷ lệ phụ thuộc trẻ & 35,0 & 31,6 & 36,1 & 30,8 & 28,6 & 32,8 \\
Tỷ lệ phụ thuộc già & 8,8 & 8,2 & 8,9 & 14,4 & 10,8 & 12,6 \\
Tỷ lệ phụ thuộc chung & 43,8 & 39,6 & 45,0 & 45,2 & 39,3 & 45,3 \\
\hline
\end{tabular}

(Nguồn: TCTK, 2009, 2019)

Về chỉ số già hóa dân số, chỉ số này là tỷ số giữa dân số 60 tuổi trở lên so với dân số dưới 15 tuổi tính theo phần trăm. Chỉ số này là một trong những cơ sở để khẳng định sự già hóa dân số. Theo kết quả điều tra dân số và nhà ở năm 2019 cho thấy, chỉ số già hóa dân số toàn vùng là $58,5 \%$ [2, tr64], tăng 24,3\% so với năm 2009 $(34,2 \%)[1, \operatorname{tr} 139]$. Có nghĩa là nhóm dân số từ 60 tuổi trở lên ở ĐBSCL có xu hướng tăng nhanh hơn nhóm dân số dưới 15 tuổi. So với cả nước, ĐBSCL có chỉ số già hóa dân số là cao nhất.

Xét theo các địa phương, ở biểu 2 đã phản ánh chỉ số già hóa dân số ở các địa phương tại ĐBSCL. Theo đó, tỉnh Bến Tre là địa phương có chỉ số già hóa dân số cao nhất và thấp nhất là tỉnh Kiên Giang. Điều này phản ánh có sự khác biệt của quá trình già hóa dân số ở các địa phương. Vì thế, các chính sách, kiến nghị thích ứng đối với già hóa dân số cần phải được tính đến đặc điểm kinh tế - xã hội của các địa phương.

Như vậy, sự biến đổi cơ cấu dân số theo nhóm tuổi ở ĐBSCL đã cho thấy, dân số ở Tây Nam bộ đang còn trong thời kỳ dân số vàng; tuy nhiên nhóm dân số từ 30-49 tuổi có xu giảm mạnh và tỷ trọng người cao tuổi (65 tuồi trở lên) có xu hướng tăng nhanh. Điều này đã làm cho tốc độ già hóa dân số ở ĐBSCL diễn ra với tốc độ nhanh. Tốc độ này có sự khác nhau giữa các địa phương trong vùng.

\subsection{Biến đổi co cấu dân số theo trình độ học vấn}

Theo kết quả điều tra dân số và nhà ở 2019, có $94,2 \%$ dân số từ 15 tuổi trở lên ở ĐBSCL biết đọc, viết, tăng $2,6 \%$ so với năm 2009. So với các vùng kinh tế - xã hội trong cả nước, tỷ lệ này chỉ cao hơn một số vùng như Tây Nguyên, Trung du và miền núi phía Bắc và thấp hơn các vùng còn lại. 
Xét về trình độ giáo dục cao nhất, theo kết quả điều tra dân số và nhà ở năm 2019 cho thấy, bức tranh về tỷ trọng dân số 15 tuổi trở lên đạt trình độ giáo dục cao nhất ở ĐBSCL có sự thay đổi không tích cực. Tỷ trọng dân số chưa tốt nghiệp tiểu học và chưa bao giờ đi học chiếm tỷ lệ khá cao. So với năm 2009, tỷ lệ này có xu hướng tăng lên. Trong khi đó, tỷ trọng dân số 15 tuổi trở lên tốt nghiệp trung học phổ thông tăng nhẹ 3,4\% so với năm 2009 (xem bảng 7).

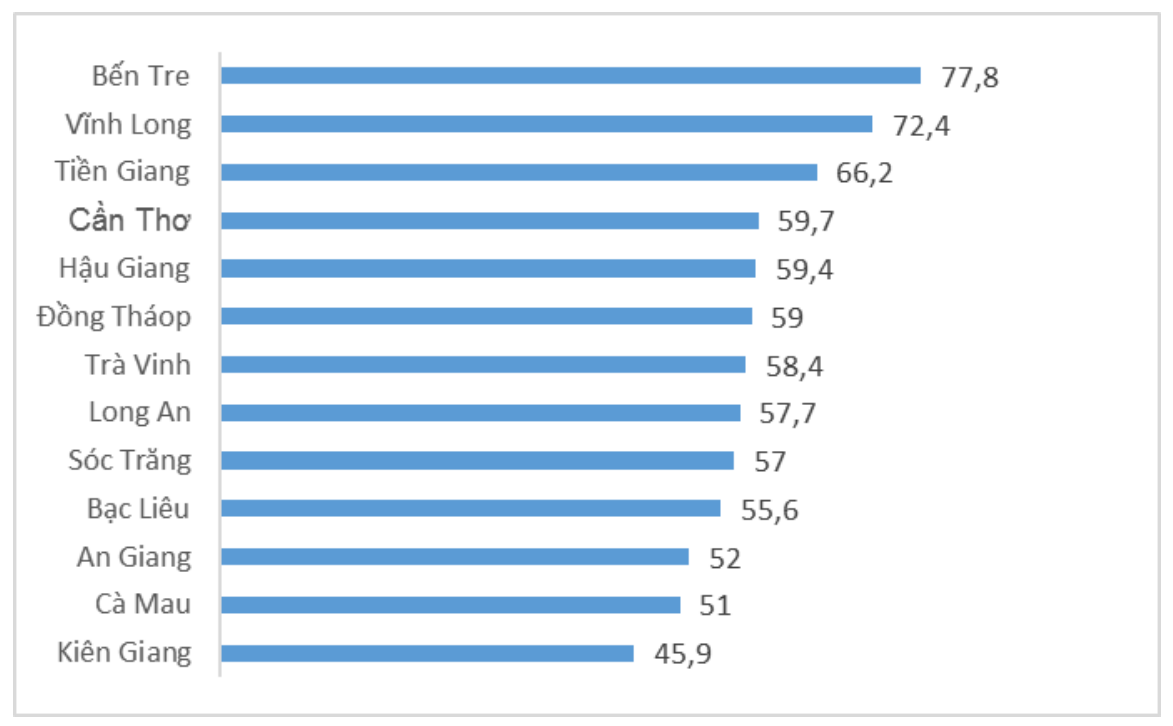

Biểu 2. Chỉ số già hóa dân số theo địa phương ở ĐBSCL (\%). (Nguồn: TCTK, 2019)

Bảng 7. Tỷ lệ dân số 15 tuổi trở lên theo trình độ giáo dục cao nhất $(\%)$

\begin{tabular}{lll}
\hline Trình độ giáo dục & 2009 & 2019 \\
\hline Chưa bao giờ đi học & 6,9 & 18,4 \\
Chưa tốt nghiệp tiểu học & 26,7 & 34,6 \\
Tốt nghiệp tiểu học & 36,1 & 26,0 \\
Tốt nghiệp THCS & 17,4 & 11,3 \\
Tốt nghiệp THPT & 6,4 & 9,7 \\
\hline
\end{tabular}

(Nguồn: TCLK, 2009, 2019)

Sở dĩ tỷ trọng dân số từ 15 tuổi ở ĐBSCL đạt trình độ giáo dục không tích cực là do tỷ lệ trẻ em ngoài nhà trường chiếm khá cao $(13,0 \%)$, cao nhất so với các vùng kinh tế - xã hội khác; bậc học càng cao thì tỷ lệ trẻ ngoài nhà trường cao, chỉ $1,8 \%$ trẻ em ngoài nhà trường ở cấp học tiểu học, trong khi đó tỷ lệ ở cấp trung học cơ sở là $12,0 \%$ và trung học phổ thông là $37,5 \%$ [2, tr121]. Thực tế cho thấy, tình trạng trẻ em bỏ học ở ĐBSCL ngày càng nhiều bởi các em bị cuốn theo dòng di chảy di cư của người lớn. Di cư có thể gây nhiều tác động đối với trẻ em vì chúng phải đối mặt với sự chia ly, cuộc sống xa cách gia đình, quá trình học tập bị gián đoạn và thiếu các mạng lưới xã hội. Trẻ em nam chủ yếu lao động trong các ngành đòi hỏi phải có sức khỏe như xúc than hay đánh bắt thủy sản, hoặc buôn bán và buôn lậu ma túy, còn trẻ em nữ thường làm lao động giúp việc gia đình, một số em bị đẩy vào con đường mại dâm $[5, \operatorname{tr} 3]$.

Xét về trình độ chuyên môn kỹ thuật (CMKT), tỷ lệ dân số 15 tuổi trở lên ở ĐBSCL được đào chuyên môn chiếm $9,7 \%$ vào năm 2019, tăng 3,1\% so với năm 2009; trong đó tốt nghiệp đại học chiếm 5,2\% của năm 2019, tăng $2,9 \%$ so với năm 2009 [2, tr125]. Đây là sự chuyển biến tích cực về cơ cấu dân số được đào tạo. Tuy nhiên, so với các vùng kinh tế- xã hội, tỷ lệ này thấp nhất trong cả nước (Đồng bằng sông Hồng: 27,9\%; Đông Nam bộ: 20,8\%; Trung du và miền núi phía Bắc: $18,1 \%$, Tây 
Nguyên: 13,9\%) [2, tr125]. So với năm 2009, tỷ lệ này tăng lên $3,1 \%$; trong khi đó ĐBSH tăng $8,5 \%$, Đông Nam bộ tăng $5,6 \%$, Trung du và miền núi phía Bắc tăng $4,4 \%$, Tây Nguyên tăng $4,1 \%[1, \operatorname{tr} 95 ; 2, \operatorname{tr} 125]$.

Bảng 8. Tỷ lệ dân số 15 tuổi trở lên theo trình độ CMKT đạt được

\begin{tabular}{lll}
\hline & 2009 & 2019 \\
\hline Tốt nghiệp sơ cấp & 1,4 & 1,1 \\
Tốt nghiệp trung cấp & 2,2 & 1,8 \\
Tốt nghiệp đại học & 0,9 & 1,6 \\
Tốt nghiệp ĐH trở lên & 2,1 & 5,2 \\
Tổng & $\mathbf{6 , 6}$ & $\mathbf{9 , 7}$ \\
\hline
\end{tabular}

(Nguồn: Tổng Cục thống kê, 2009, 2019)

Có thể nói, trong 10 năm qua, tỷ lệ dân số được đào tạo CMKT ở ĐBSCL có thay đổi nhưng chậm hơn so với các vùng kinh tế- xã hội khác, cho nên trình độ chuyên môn của dân số ở ĐBSCL vẫn duy trì ở vị trí thấp nhất. Điều này có nghĩa rằng, ĐBSCL vẫn chưa thoát khỏi "vùng trũng" về trình độ giáo dục của cả nước.

\section{Một số vấn đặt ra và kiến nghị hàm ý chính sách}

\subsection{Một số vấn đề đặt ra}

Thứ nhất, trong 10 năm (2009-2019), tỷ số giới tính dân số và tỷ số giới tính khi sinh ở ĐBSCL tương đối ổn định và vẫn duy trì ở tỷ số có thể chấp được so với mức bình thường (104-106 bé trai/bé gái). Tuy nhiên, tỷ số giới tính khi sinh ở từng địa phương có sự khác nhau, cho nên nguy cơ mất cân bằng giới tính xảy ra ở một số địa phương. Từ thực trạng về tỷ số giới tính khi sinh ở ĐBSCL hiện nay thì mất cân bằng giới tính khi sinh không phải là vấn đề nghiêm trọng của khu vực này. Sở dĩ là do không chỉ thực hiện tốt công tác tuyên truyền, giáo dục mà còn định kiến sinh con trai, con gái ở ĐBSCL không quá khắt khe. Điều này không có nghĩa là không có nguy cơ mất cân bằng giới khi sinh, bởi vì tỷ số giới tính khi sinh ở ĐBSCL không ổn định qua các năm. Riêng ở một số địa phương đang có nguy cơ mất cân bằng giới tính thì cần phải có những giải pháp để kiểm soát và đưa tỷ số giới tính khi trở lại mức cân bằng tự nhiên. Do đó, việc chủ động kiểm soát tỷ số giới khi sinh và giảm thiểu tác động của vấn đề này là một trong những nhiệm vụ của công tác dân số ở ĐBSCL trong tình hình mới.

Bên cạnh đó, thực trạng về biến đổi tỷ số giới tính dân số theo xu hướng nhóm tuổi càng cao thì tỷ số giới tính càng giảm. Điều này dẫn đến tình trạng nữ hóa trong người cao tuổi. Thực tế này đã chứng minh qua tuổi thọ trung của phụ nữ và nam giới, tuổi thọ trung bình của dân số ở ĐBSCL là 75 tuổi, trong đó 72,6 tuổi đối với nam và 77,5 tuổi đối với nữ $[4, \operatorname{tr} 233]$.

Thứ hai, biến đổi cơ cấu dân số về tuổi là một trong những tác động rất lớn đối với phát triển kinh tế - xã hội ở ĐBSCL nói riêng, cả nước nói chung. Cấu trúc dân số, đặc biệt là cấu trúc tuổi có tác dụng thúc đẩy thị trường lao động phát triển trong thời kỳ cơ cấu dân số "vàng"[6]. Vì thế, nghiên cứu của UNFPA và Viện nghiên cứu chiến lược đã khẳng định, nếu dân số trong độ tuổi lao động tăng thêm $1,0 \%$ thì tăng trưởng kinh tế tăng thêm khoảng $0,5 \%$ và cứ tăng $1,0 \%$ dân số có việc làm của nhóm tuổi từ 15-59 và nhóm từ 60 tuổi trở lên thì GDP sẽ tăng tương ứng là $0,36 \%$ và $0,32 \%[7$, tr4]. Thực trạng biến đổi cơ cấu dân số về độ tuổi đã cho thấy, ĐBSCL là một trong những vùng kinh tế - xã hội có lợi thế lực lượng dân số trong độ tuổi 15-64 chiếm tỷ lệ khá cao và duy trì khá ổn định trong 10 năm qua. Có nghĩa là, ĐBSCL đang có lợi thế rất lớn về dân số vàng đối với sự phát triển kinh tế - xã hội của vùng đất chín rồng. Mặc dù vậy, ĐBSCL vẫn chưa tận dụng lợi thế này bởi vì tình trạng thất nghiệp của lực lượng lao động trong độ tuổi lao động chiếm $2,51 \%$ [4, tr 290], trong đó thất nghiệp ở nhóm tuổi 15-24 chiếm 9,24\% [4, tr293]. Trong khi đó, tỷ trọng dân số từ 30-49 tuổi có $x u$ hướng giảm và tăng nhanh ở nhóm tuổi từ 50-64 tuổi trong 10 năm qua. Điều này cho thấy, có sự già hóa trong lực lượng lao động ở ĐBSCL. Cộng với tỷ lệ phụ thuộc già và chỉ số già hóa dân số tăng nhanh từ năm 2009 đến năm 2019 đã đặt ra một thách thức đối với ĐBSCL, đó là già hóa dân số. 
Mặc dù, các nghiên cứu chỉ ra rằng, vấn đề già hóa dân số là một thành tựu đáng kể của đất nước bởi vì nó chứng tỏ được điều kiện sống của con người đã được an toàn, thu nhập khá hơn, dinh dưỡng tốt, hệ thống chăm sóc sức khỏe đầy đủ hơn $[8, \operatorname{tr} 57-65]$ và phản ánh thành tựu phát triển về kinh tế, xã hội, $\mathrm{y}$ tế và công tác dân số [9, tr 77-86]. Con người sống lâu hơn là do chế độ dinh dưỡng, vệ sinh, tiến bộ y học, chăm sóc y tế, giáo dục và đời sống kinh tế ngày càng tốt hơn [10]. Song, già hóa dân số cũng tạo ra nhiều thách thức đối với tài chính của Chính phủ, cơ cấu chi tiêu của chính phủ, hệ thống chăm sóc sức khỏe, an sinh xã hội, làm gia tăng sự vô cảm đối với người cao tuổi trong xã hội... Có thể nói, vấn đề đặt ra cho phát triển kinh tế - xã hội ở ĐBSCL là làm thế nào để tận dụng lực lượng lao động dồi dào, hạn chế tình trạng thất nghiệp để không phải đánh mất cơ hội dân số vàng. Trong khi đó, già hóa dân số là một tất yếu của quá trình phát triển và xu hướng này ở ĐBSCL đang diễn ra khá nhanh. Vì thế, nếu không tận dụng cơ hội này thì ĐBSCL sẽ rơi vào tình trạng "già trước khi giàu".

Thứ ba, trình độ học vấn và trình độ chuyên môn của dân số ở ĐBSCL còn khá thấp so với các vùng kinh tế - xã hội. Trong thời gian qua, toàn hệ thống chính trị ở ĐBSCL đã có nhiều sự nỗ lực đối với nâng cao trình độ cho người dân; song qua kết quả điều tra dân số và nhà ở năm 2019 cho thấy, ĐBSCL chưa thoát khỏi "vùng trũng" về giáo dục của cả nước. Bởi lẽ, tình trạng trẻ em ngoài nhà trường, dân số chưa qua đào tào chiếm tỷ lệ cao so với các vùng kinh tế - xã hội khác của cả nước. Tỷ lệ dân số ở trong độ tuổi đi học trung học phổ thông nhưng không đi học chiếm 37,5\% [4, tr 262]; tỷ lệ này ở độ tuổi trung học cơ sở là $12,0 \%$ [4, tr260]. Tỷ lệ dân số từ 15 tuổi trở lên không qua đào tạo chiếm $90,3 \%$ [2, tr125]. Chính điều này đã ảnh hưởng chất lượng của lực lượng lao động của toàn vùng và tạo áp lực rất lớn về đào tạo trình độ chuyên môn, đào tạo nghề, giải quyết việc làm cho lực lượng lao động ở ĐBSCL trong bối cảnh dân số vàng.

\subsection{Kiến nghị hàm ý chính sách}

Tại Hội nghị lần thứ 6 của Ban Chấp hành Trung ương khóa XII, Đảng ta đã nêu rõ, "Dân số là yếu tố quan trọng hàng đầu của sự nghiệp xây dựng và bảo vệ Tổ quốc. Công tác dân số là nhiệm vụ chiến lược, vừa cấp thiết vừa lâu dài; là sự nghiệp của toàn Đảng, toàn dân" [11]. Vì thế, mục tiêu quan trọng thực hiện công tác dân số trong tình hình mới là phải "giải quyết toàn diện, đồng bộ các vấn đề về quy mô, cơ cấu, phân bổ, chất lượng dân số và đặt trong mối quan hệ tác động qua lại với phát triển kinh tế xã hội. Duy trì vững chắc mức sinh thay thế; đưa tỉ số giới tính khi sinh về mức cân bằng tự nhiên; tận dụng hiệu quả cơ cấu dân số vàng, thích ứng với già hóa dân số; phân bố dân số hợp lý; nâng cao chất lượng dân số, góp phần phát triển đất nước nhanh, bền vững" [11]. Như vậy, từ bằng chứng về biến đổi cơ cấu dân số ở ĐBSCL, một số kiến nghị hàm ý về chính sách được gợi mở như sau:

Một là, tiếp tục truyền thông về bình đẳng giới và các biện pháp giảm thiểu tác động của mất cân bằng giới tính khi sinh trong mọi tầng lớp nhân dân. Ngoài ra, cần có các biện pháp kiểm soát việc xử lý nghiêm hơn nữa đối với các hành vi lựa chọn giới tính thai nhi. Thúc đẩy bình đẳng giới trong các lĩnh vực của đời sống xã hội, giảm tính dễ tổn thương của người già, đặc biệt nữ giới trong nhóm tuổi này. Tăng cường lồng ghép kiến thức bình đẳng giới vào các môn học ở các cấp bậc học và trong chương trình đào tạo lý luận chính trị.

Hai là, xây dựng hệ thống các giải pháp để thích ứng và làm chậm lại quá trình già hóa dân số ở ĐBSCL. Trong đó, chú ý đến nâng cao chất lượng công tác chăm sóc sức khỏe ban đầu cho nhân dân; phát triển hệ thống dịch vụ chăm sóc người cao tuổi; tuyên truyền nâng cao nhận thức về tự rèn luyện sức khỏe và xây dựng lối sống lành mạnh; đầu tư hệ thống kết cấu hạ tầng đảm bảo an toàn cho người cao tuổi; đẩy mạnh nghiên cứu liên quan đến người cao tuổi ở ĐBSCL...

Ba là, sử dụng và tận dụng một cách triệt để lợi thế của cơ cấu dân số vàng. Để làm được 
điều này, trước hết cần có giải pháp liên quan đến giáo dục - đào tạo để xóa bỏ "vùng trũng" về trình độ giáo dục ở ĐBSCL, đáp ứng yêu cầu phát triển kinh tế - xã hội trong bối cảnh công nghiệp 4.0. Đó là đầu tư giáo dục, đẩy mạnh phổ cập giáo dục... Tiếp đến, cần có các giải pháp tạo và giải quyết việc làm cho lực lượng lao động được đào tạo như hỗ trợ vay vốn tín dụng tạo việc làm, thu hút đầu tư, tiếp tục đẩy mạnh xây dựng nông thôn mới.

Bốn là, rà soát và hoàn thiện chính sách dân số. Thực tế cho thấy, chính sách dân số là một trong những nguyên nhân dẫn mất cân bằng giới tính khi sinh, già hóa dân số. Bởi vì, từ khi thực hiện chính sách dân số - kế hoạch hóa gia đình theo tinh thần Nghị quyết 04NQ/HNTW, mục tiêu chính sách dân số chủ yếu tập trung vào giảm mức sinh với tinh thần "mỗi cặp vợ chồng có từ 1-2 con". Điều này đã khiến cho nhiều cặp vợ chồng phải lựa chọn giới tính thai nhi, đặc biệt là các cặp vợ chồng bị kiểm soát bởi các chế tài liên quan đến thực hiện chính sách dân số. Đồng thời, sau gần 30 năm thực hiện Nghị quyết này, mức sinh giảm ở ĐBSCL giảm mạnh và đây là một trong những nguyên nhân làm cho già hóa dân số diễn ra nhanh. Do đó, trong bối cảnh dân số ĐBSCL nói riêng, cả nước nói chung đang bước vào quá trình già hóa và có nguy cơ mất cân bằng giới tính khi sinh, việc rà soát và hoàn thiện chính sách theo hướng thích ứng già hóa dân số và giảm nguy cơ mất cân bằng giới tính khi sinh cần được thực hiện một cách nghiêm túc và chặt chẽ. Chính sách dân số cần được xây dựng dựa trên quan điểm "tiếp tục chuyển trọng tâm chính sách dân số từ kế hoạch hóa gia đình sang dân số và phát triển. Công tác dân số phải chú trọng toàn diện các mặt quy mô, cơ cấu, phân bố, đặc biệt là chất lượng dân số và đặt trong mối quan hệ hữu cơ với các yếu tố kinh tế, xã hội, quốc phòng, an ninh và bảo đảm phát triển nhanh, bền vững" [11].

\section{Tài liệu tham khảo}

[1] General Statistics office, Population and Housing census 2009, Statistical Publising house, Ha Noi, 2009 (In Vietnamese).

[2] General Statistics office, Population and Housing senus 2019, Statistical Publising house, Ha Noi, 2019. (In Vietnamese).

[3] UNFPA, Sex ratio at birth in Asia and Vietnam: Literature review to guide policy research, Hanoi, 2010. (In Vietnamese).

[4] General Statistics Office, Appendix of Results of the Population and Housing Census 2019, Statistical Publishing House, Hanoi, 2019. (In Vietnamese).

[5] UN, Migration, Resettlement and Climate Change in Viet Nam, Hanoi, 2014. (In Vietnamese).

[6] Lyluanchinhtri, Shift in structural age of population and labor market (Accessed February, 22 $\left.{ }^{\text {nd }}, 2020\right)$. (In Vietnamese)

http://lyluanchinhtri.vn/home/index.php/thuc -tien/item/773-bien-doi-cau-truc-tuoi-danso-va-thi-truong-lao-dong.html,

[7] UNFPA and Institute of Strategic Studies, Impact of population age change on Vietnam's economic growth and policy proposals, Briefing Report, 2017 (In Vietnamese).

[8] Le Thi, The trend of population aging in Vietnam and promoting the positive role of the elderly, Journal of Social Sciences 5 2011 (57-65) ((In Vietnamese).

[9] Le Van Kham, The issue of the elderly in Vietnam today, Vietnam Journal of Social Science $7 \quad$ (80) $2014 \quad$ (77-86). (In Vietnamese).

[10] UNFPA and helpAge Inernational, Aging in the 21st Century: Achievements and Challenges, Brief Report, Hanoi, 2012 (In Vietnamese).

[11] Central Committee of Communist Party (2017), Resolution 21-NQ / TW "Population task in the new situation". (In Vietnamese). 